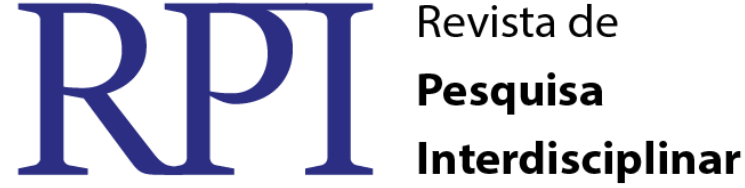

\section{O USO DA CALCULADORA NOS ANOS INICIAIS: OUTRA MANEIRA DE CHEGAR AO RESULTADO}

\author{
Marcela Ferreira Lopes - UFCG \\ Cátia Larissi Mendes Dias- UFCG \\ Géssica Galdino da Silva Pereira- UFCG
}

\begin{abstract}
RESUMO
O objetivo deste trabalho é analisar como está sendo trabalhado o uso da calculadora na resolução de problemas durante as aulas de matemática nos anos iniciais em uma escola pública da cidade de Cajazeiras-PB e outra da cidade de Ipaumirim-CE, identificando se a mesma está sendo utilizada como instrumento pedagógico por parte do(a)s professore(a)s na mediação de conteúdos, frente aos problemas que envolvam operações simples ou complexas. Através da entrevista semiestruturada foi possível perceber que os professores consideram relevante o uso da calculadora em sala, porém, em determinados momentos, os mesmos não recomendam tal uso no momento em que os alunos estão apreendendo o conteúdo, mas após os alunos assimilarem o conteúdo exposto os educadores não observam dano algum na utilização dessa ferramenta pedagógica na resolução de problemas. A partir da análise dos dados dos alunos observamos que os mesmos não tinham estímulo por parte do professor para utilizarem a calculadora durante as aulas. Através de questões -problemas verificamos que os educandos constroem o cálculo mentalmente para depois verificarem na calculadora o resultado final, se este é condizente com o que eles consideram correto. Nessa perspectiva, a calculadora apenas auxilia ao aluno a verificação do resultado mais preciso.
\end{abstract}

Palavras-chave: Matemática, Calculadora, Resolução de problemas.

\section{THE USE OF THE CALCULATOR IN THE INITIAL YEARS: ANOTHER WAY TO GAIN THE RESULT}

\begin{abstract}
The objective of this work is to analyze how the calculator is being used in problem solving during math classes in the initial years of a public school in the city of Cajazeiras-PB and another one in the city of Ipaumirim-CE, identifying whether it is Being used as a pedagogical tool on the part of the teachers in the mediation of contents, in the face of problems that involve simple or complex operations. Through the semi-structured interview it was possible to see that teachers consider the use of the calculator in the classroom relevant, but at certain moments they do not recommend such use at the moment when the students are seizing the content, but after the students assimilate the exposed content The educators do not observe any harm in the use of this pedagogical tool in the resolution of problems. From the analysis of the data of the students we observed that they did not have stimulus on the part of the teacher to use the calculator during the classes. Through questions-problems we find that the learners construct the calculation mentally and then check the calculator for the final result, if it is in accordance with what they consider correct. From this perspective, the calculator only helps the student to verify the most accurate result.
\end{abstract}

Keywords: Mathematics, Calculator, Problem solving.

\section{INTRODUÇÃO}


Como bem sabemos, a sociedade contemporânea está totalmente inserida em contextos tecnológicos. Prova disso é que se faz constantemente uso de tecnologias cada vez mais avançadas. No âmbito escolar, pode- se imaginar que o uso das calculadoras em sala de aula ainda constitui-se em assunto polêmico pela maioria dos professores "matemáticos", por não possuírem uma formação adequada para utilizarem-se da calculadora e, ao mesmo tempo, mostrar aos seus referidos alunos outras maneiras/formas de se chegarem ao resultado. Pensando nisso, realizamos uma pesquisa com a finalidade de analisar como vem sendo trabalhado o uso da calculadora na resolução de problemas durante as aulas de matemática nos anos iniciais. A partir disso, delineamos o uso da calculadora como o nosso objeto de estudo na intensificação de uma aprendizagem significativa por parte dos alunos.

Ser professor de matemática implica vários desafios no que concerne a dinâmica em sala de aula por na maioria das vezes os alunos não simpatizarem da disciplina e apresentar inúmeras dificuldades na assimilação de conteúdos matemáticos. Daí a importância do profissional docente desenvolver estratégias pedagógicas que propiciem ao aluno o desenvolvimento cognitivo. Nesse caso o uso da calculadora é um instrumento de grande valia para subsidiar a aprendizagem nas aulas de matemática, estimulando o raciocínio lógico bem como habilidades que o cotidiano exige na resolução de problemas.

\section{A Educação Matemática No Contexto Brasileiro: Ser Professor E O Que/Como Ensinar?}

Ensinar matemática nos dias atuais exige uma nova compreensão da que se tinha antes, minimizando a matemática como um saber pronto e acabado. Seu ensino hoje requer uma compreensão mais abrangente na formação do cidadão. Nesse sentido Fiorentine (1995) apud Maccarini (2010, p.16) corrobora que

A matemática, sob o ponto de vista histórico- crítico não pode ser concebida como um saber pronto e acabado, mas, ao contrário, como um saber vivo, dinâmico e que, historicamente, vem sendo construído, atendendo a estímulos externos (necessidades sociais) e internos (necessidades teóricas de ampliação dos conceitos).

RPI Revista de Pesquisa Interdisciplinar, Cajazeiras, v. 1, Ed. Especial, 370 - 380, set/dez. de 2016. 
O que? para que? e a quem ensinar matemática são indagações relevantes em se tratando de seu ensino, visto que, nenhuma sala de aula é homogênea e que nenhum aluno é igual ao outro, possuindo assim tempo de aprendizagem distintos. Dessa forma cabe ao professor apropriar-se de metodologias e recursos adequados e condizentes para a mediação dos conteúdos. Compreender se a aprendizagem dos conteúdos é significativa na vida escolar e social do aluno e como esse ensino contribui para a formação do ser crítico em meio à sociedade é algo também a ser pensado em se tratando desse ensino. Esse novo modelo se concretiza nas palavras de D’Ambrósio (1993, p.14) apud Maccarini (2010, p.32) quando afirma que:

[...] a educação matemática não depende de revisões de conteúdos, mas da dinamização da própria matemática, procurando levar novas práticas à geração de conhecimento. Tampouco depende de uma metodologia "mágica". Depende essencialmente de o professor assumir sua posição, reconhecer que ele é companheiro de seus estudantes na busca de conhecimento, e que a matemática é parte integrante deste conhecimento que dia a dia se renova e se enriquece pela experiência vivida por todos os indivíduos deste planeta.

Como se sabe, ocorrem vários impasses no que se refere à profissão docente no Brasil, mais especificamente a de professor na área de Matemática, no qual se apresenta ser um (grande) desafio para todos aqueles que são formados nessa área. Inicialmente o profissional se depara na maioria das vezes com mais da metade da turma "detestar" a disciplina e os que sobram (cerca de 2 ou 3 alunos) os que realmente apreciam, serem considerados como "privilegiados" por gostarem e aprenderem Matemática. Para tanto, o professor se depara com dilemas: o que fazer que métodos usar, para os que não gostam de Matemática passe então a olhar com outros olhos a tão temida disciplina? Diante disso, Muniz, (2003, p.8) enfatiza que ser professor

[...] requer, minimamente, dominar os conteúdos matemáticos que serão objetos de ensino. [...] Além disso, é necessário ter uma base sobre como se aprende matemática, como o professor pode colocar-se como um mediador no processo de aquisição desse conhecimento, que conteúdos são necessários para a formação do cidadão. 
O profissional, além de ser um mediador do processo de ensino e aprendizagem, deve fazer do espaço com que aconteça a aula de matemática nos anos iniciais de descobertas e não ministrar a aula reproduzindo velhas formas e teoremas ou simplesmente "armando continhas" totalmente desconectadas do cotidiano do educando. Considera-se um bom professor de matemática aquele que conhece todas as fórmulas, teorias e variações dos números; que interpreta gráficos e tabelas que tem a capacidade de fazer em pouco tempo, uma conta de cabeça e dar o resultado preciso. Porém, afirma Muniz (2003, p.9) que "antes de dominar esses conteúdos, o bom professor de matemática deve estar disponível a APRENDER SEMPRE, a partir das situações impostas pelos desafios da vida, do magistério e da vida cotidiana dentro da nossa cultura". Sempre levando em consideração o conhecimento prévio que cada aluno possui.

Uma das grandes discussões impostas ao ensino de matemática é o uso da calculadora, algo que constitui assunto delicado e polêmico, visto que, tal uso ainda é questionável por alguns profissionais se é aceitável ou não na sala de aula. Partindo de algumas inquietações pessoais, procuraremos discutir o uso da calculadora na sala dos anos iniciais como uma ferramenta pedagógica favorável à aprendizagem na resolução de problemas em se tratando de adição, subtração, multiplicação e divisão. A intensão não é substituir o cálculo escrito e mental, mas, estimular nos educandos a curiosidade em procurar outras formas de resolver problemas com o uso da calculadora, ganhando assim o máximo de tempo e a verificação do resultado mais preciso. Uma vez que seu uso é autorizado pelos PCN's. Nesse sentido, afirma D’Ambrosio (1986, p.56)

Hoje, todo mundo deveria estar utilizando a calculadora, uma ferramenta importantíssima. Ao contrário de que muitos professores dizem, a calculadora não embota o raciocínio do aluno- todas as pesquisas feitas sobre a aprendizagem demonstram isso.

Nessa perspectiva o professor encontra-se em uma posição favorável, pois o mesmo tem em mãos o recurso tecnológico que possibilita ser utilizado de maneira eficiente o desenvolvimento do raciocínio frente a resolução de problemas. Mas o que vemos na realidade é que, na grande maioria, os educadores não inserem o uso dessa ferramenta nas aulas, se detendo tão somente à resolução de operações, tendo como subsídio o famoso livro didático e a memorização da tabuada. É por demais sabido que a calculadora configura-se 
como uma das tecnologias que auxilia o trabalho do professor e um recurso que estimula a aprendizagem do alunado, sendo considerado mais um instrumento básico de relevância ímpar para realização de diversas atividades. Com base nos PCN’s (1997, p.34) enfatiza que

\begin{abstract}
Estudos e experiências evidenciam que a calculadora é um instrumento que pode contribuir para a melhoria do ensino da Matemática. A justificativa para essa visão é o fato de que ela pode ser usada como um instrumento motivador na realização de tarefas exploratórias e de investigação Além disso, ela abre novas possibilidades educativas, como a de levar o aluno a perceber a importância do uso dos meios tecnológicos disponíveis na sociedade contemporânea.
\end{abstract}

Vale salientar que a calculadora nos contextos educacionais tem pouco ou quase nenhuma função, pelo fato que tanto o professor não tem uma formação adequada para a devida utilização, nem o aluno tem a chance de utilizá-la em sala de aula pelo fato que professores alegam que a mesma atrapalha o desenvolvimento cognitivo. As aulas se resumem, na grande maioria, em armar e efetuar contas no caderno, desconsiderando as situações-problemas que no enunciado da questão instiguem o aluno a raciocinar sobre o problema e com a ajuda da calculadora verificar os possíveis resultados.

\title{
Metodologia
}

A pesquisa foi realizada em duas Escolas municipais: uma situada na cidade de Cajazeiras-PB, outra situada na cidade de Ipaumirim- CE. Os sujeitos envolvidos foram dois professores que ministram aulas de Matemática porém, possuem formação em Letras. Sendo um do sexo masculino (professor A) e o outro do sexo feminino (professora B) e 3 alunos na faixa entre 10 e 12 anos. Ambos do $5^{\circ}$ ano dos anos iniciais.

A coleta de dados se deu a partir de uma entrevista semiestruturada com a utilização de um roteiro previamente elaborado com 2 perguntas destinadas aos professores com a finalidade de conhecer a concepção destes acerca da calculadora como recurso pedagógico nas aulas de matemática. Em seguida, aplicamos um conjunto 2 perguntas aos 3 alunos (todos do sexo masculino) constituída por uma questão de nível médio bem como uma questão de nível difícil. Os alunos foram identificados da seguinte forma: aluno 1: HC, Aluno 2: PJ e aluno 3: MK.

RPI Revista de Pesquisa Interdisciplinar, Cajazeiras, v. 1, Ed. Especial, 370 - 380, set/dez. de 2016. 


\section{Análise Dos Dados Acerca Dos Professores}

Inicialmente propomos aos professores alguns questionamentos com relação ao uso da calculadora em sala de aula e a relevância de ensinar e aprender matemática. A primeira pergunta foi: $O$ que você pensa do uso da calculadora em sala de aula? Por quê??

O professor A manifestou-se da seguinte forma: nas operações simples, quando começamos a trabalhar o assunto, eu não aconselho o uso da calculadora, mas depois que o aluno domina ou compreende as etapas das operações, acho que não há prejuízo o uso da calculadora.

Podemos perceber que a resposta da pergunta é clara e objetiva, pois o professor inicialmente se manifesta diante da pergunta, contrário ao uso da calculadora. Porém, o mesmo afirma que o aluno depois de compreender o conteúdo, o educador não vê prejuízo algum no uso da calculadora pelos alunos. Vale salientar que o mesmo não possui a formação adequada para atuar nos anos iniciais, sendo sua graduação em Letras. Nesse sentido, o PCN de Matemática (1997, p.35) diz que a calculadora é apontada como "um instrumento que traz versáteis possibilidades ao processo de ensino e aprendizagem de Matemática, seja pela sua destacada presença na sociedade moderna, seja pelas possibilidades de sua aplicação nesse processo".

A professora B respondeu da seguinte forma: a favor, pois a calculadora é um instrumento utilizado para aprimorar a prática, os conhecimentos da criança.

Diante da resposta pudemos analisar que a professora mostrou-se a favor do uso de tal instrumento. O que podemos perceber é que a professora, apesar de ter sua formação na área de Letras, detém conhecimentos específicos para os anos iniciais, considerando relevante o auxílio da calculadora na aprendizagem dos educandos. Referente a isso o Parâmetro Curricular Nacional de Matemática (1997, p.35) mais uma vez diz que a calculadora "pode ser um grande aliado do desenvolvimento cognitivo dos alunos, principalmente na medida em que ele permite um trabalho que obedece a distintos ritmos de aprendizagem".

Ambos os professores consideram relevante o uso da calculadora, como subsídio ao ensino e aprendizagem da matemática nos anos iniciais de forma bastante significativa. $\mathrm{O}$ professor $\mathbf{A}$ acredita que o momento propício e adequado para utilização da calculadora seria posteriormente à aprendizagem das operações básicas que o aluno assimila durante as aulas.

RPI Revista de Pesquisa Interdisciplinar, Cajazeiras, v. 1, Ed. Especial, 370 - 380, set/dez. de 2016. 
Diferentemente do professor A, a professora B considera que a calculadora deve ser utilizada na aprendizagem das operações mais simples, não identificando o momento apropriado para que a calculadora se faça presente.

A segunda pergunta proposta por nós aos professores foi: com relação ao uso da calculadora em sala de aula: ela ajuda o aluno na resolução de problemas ou dificulta o processo de ensino e aprendizagem? O professor A respondeu a assertiva da seguinte forma: como já citei na questão 1 ela pode sim ser útil ao aluno no processo da aprendizagem, desde que ele já saiba fazer estimativas ou seja, quando ele já tem consciência do que ele está fazendo e a utilize apenas para tirar dúvidas.

Pode-se perceber que o professor apenas enaltece o que foi dito da questão anterior considerando relevante o uso da calculadora no processo ensino-aprendizagem. Nesse sentido a calculadora configura-se como um instrumento pedagógico para a verificação de resultados, ou seja, o aluno em primeiro lugar deve demonstrar por escrito o que internalizou sobre o assunto e se apropriar da calculadora para comparar os resultados se os mesmos estão corretos ou não.

A resposta da professora B se deu da seguinte forma: dinâmica, proveitosa, ajuda o aluno na resolução de problemas, é preciso que faça esse uso com moderação e de forma adequada.

A professora B considera relevante o uso da calculadora no lócus de ensino para que a aula de matemática seja mais proveitosa no que diz respeito à resolução de problemas. No entanto, a educadora deixa transparecer que não é sempre que deve ser usada à calculadora.

Percebe-se que a resposta da questão entre os dois professores (A e B) são semelhantes na medida em que estes consideram a calculadora importante para a verificação de resultados desde que os alunos já possuam algumas noções do conteúdo referente aos problemas em que o uso da calculadora se faça presente, tornando a aula, dessa forma, mais dinâmica e significativa.

\section{Análise Dos Dados Acerca Dos Alunos}

No que se refere à pesquisa voltada para os alunos, pode-se perceber que todos que participaram já possuíam certo conhecimento de como usar a calculadora na resolução de RPI Revista de Pesquisa Interdisciplinar, Cajazeiras, v. 1, Ed. Especial, 370 - 380, set/dez. de 2016. 
problemas, identificando as funções básicas das teclas contidas na calculadora: $O N / C$ ou $C$, $C E$ e $O F F$. Inclusive as teclas de adição +, subtração - divisão / e multiplicação X. Maccarini (2010, p. 36) afirma que "os objetivos da educação matemática deve favorecer o desenvolvimento das diversas formas de expressar o pensamento e o conhecimento matemático, seja por meio da oralidade ou do registro".

O primeiro problema apresentado constituiu no seguinte questionamento:

- Suponha que a calculadora estragou o número 0 como você faria para aparecer no visor o número: (A)0? (B)30? (C)60? (D)90?

Já aluno 1: HC fez os procedimentos da seguinte maneira:
a) $2-2=0$
c) $15 \times 4=60$
b) $15+15=30$
d) $85+5=90$

O aluno 2: PJ fez as seguintes operações:
a) $2-2=0$
c) $75-15=60$
b) $25+5=30$
d) $85+5=90$

O aluno 3: MK solucionou o problema proposto da seguinte forma:
a) $3-3=0$
c) $4 \times 15=60$
b) $16+14=30$
d) $115-25=90$

De início todos os alunos sentiram dificuldade ao ler a questão. Posteriormente, com mais calma, compreenderam o que a questão pedia e resolveram o problema. No decorrer da resolução da resposta pudemos observar que os mesmos construíam o cálculo mentalmente para depois usar a calculadora. Nesse caso a calculadora servia como uma verificação de resultado. Nesse sentido os PCN’s (1997, p.56) falam que o ensino de matemática deve levar o aluno a "ampliar os procedimentos de cálculo [...] pelo conhecimento de regularidades dos fatos fundamentais, de propriedades das operações e pela antecipação e verificação de resultados". Foi a partir dessa questão que percebemos que os alunos não utilizavam de forma nenhuma a calculadora em sala durante as aulas de matemática, porém já a conheciam previamente quanto a sua utilidade visto que os mesmos pensavam durante um certo intervalo de tempo para depois digitar na calculadora a operação de cada assertiva do problema posto.

A última situação problema apresentada, versa da seguinte maneira:

RPI Revista de Pesquisa Interdisciplinar, Cajazeiras, v. 1, Ed. Especial, 370 - 380, set/dez. de 2016. 
João Pedro gosta de brincar com sua calculadora. Assim, ele pede ao amigo Marcelo que siga a seguinte sequência:

I- $\quad$ Digite qualquer número de 3 dígitos (o número secreto);

II- $\quad$ Multiplique esse número por 10;

III- Subtraia o número secreto do número obtido;

IV- $\quad$ Divida o resultado pelo número secreto;

$V$ - $\quad$ Multiplique esse número por ele mesmo;

VI- $\quad$ Some 29.

VII-

Então, João Pedro anuncia com grande alegria, o resultado obtido, que é igual a: a) 36 b)91 c) 100 d) 110 e) 144

Ao analisamos os dados dos 3 alunos percebemos que apenas um aluno (HC) chegou ao resultado correto.

Ressalta-se que o mesmo fez o cálculo mentalmente para depois utilizar tal ferramenta pedagógica como verificação de resultado. A referida questão foi escolhida propositadamente por envolver as quatro operações matemáticas em um só problema e verificar se os alunos sabiam reconhecer a função de cada operação. Diante disso o PCN de matemática traz em seus critérios de avaliação que o aluno

[...] saiba calcular com agilidade utilizando-se de estratégias pessoais e convencionais, distinguindo as situações que requerem resultados exatos ou aproximados. É importante também avaliar a utilização de estratégias de verificação de resultados, inclusive os que fazem o uso da calculadora. (BRASIL, 1997, p.63)

Os demais alunos (2 e 3) mediante a pesquisa não conseguiram desenvolver nenhum resultado estimado nas alternativas apresentada na questão. Tais alunos apresentaram grandes dificuldades por não compreenderem o enunciado da questão, sendo assim as respostas não foram condizentes com os valores estipulados na questão. Dessa forma a calculadora constituiu de um mero instrumento que não auxiliou e nem tão pouco prejudicou a resolução de problemas. Nessa perspectiva os PCN’s (1997, p.55) corroboram que as operações devem se realizar com o foco "na compreensão dos diferentes significados de cada uma delas, nas relações existentes entre elas e no estudo reflexivo do cálculo, contemplando diferentes tiposexato e aproximado, mental e escrito".

RPI Revista de Pesquisa Interdisciplinar, Cajazeiras, v. 1, Ed. Especial, 370 - 380, set/dez. de 2016. 


\section{Considerações Finais}

Diante das análises ficou implícito o objetivo do nosso trabalho. Conhecendo se o professor possui habilidades ou conhecimento para trabalhar com a calculadora como ferramenta pedagógica que auxilia a aprendizagem qualitativa dos alunos em sala de aula e fora dela na resolução dos mais variados problemas, bem como se os alunos utilizam a mesma para o desenvolvimento de seu raciocínio ou a utilizam simplesmente para a verificação de resultado.

A calculadora é uma ferramenta pedagógica que permite ao aluno a verificação do resultado, propiciando ainda a redução de tempo gasto na resolução de problemas, visto que não existe estudo que comprove que a calculadora atrapalhe o desenvolvimento do raciocínio e nem impede que o aluno pense em como resolver os problemas mediante as explicações do professor em sala de aula, sendo observado que seu uso é pouco explorado.

De acordo com a análise dos dados, tendo como parâmetro o universo educacional, percebe-se que os professores não tem uma formação adequada para usar corretamente a calculadora, como alternativa para intensificar a aprendizagem dos conteúdos. Vale salientar que a calculadora é de relevância ímpar nas etapas que abrangem os assuntos da matemática, principalmente os que versam sobre resolução de problemas.

\section{REFERENCIAS}

BRASIL. Ministério da educação e cultura. Secretaria de educação fundamental. Parâmetros Curriculares Nacionais- PCN. Brasília: MEC/ SEF, 1997.

D’AMBROSIO, Ubiratan. Da realidade á ação: reflexos sobre educação e matemática. São Paulo: Summus: UNICAMP, 1986.

EVES, Howard. INTRODUÇÃO a história da matemática/ tradução Hygino $\mathrm{H}$. Domingues. $5^{\circ}$ ed. Campinas, SP: Ed. Da UNICAMP, 2011.

MACCARINI, Justina Motter. Fundamentos e metodologias do ensino de matemática. Curitiba: Editora Fael, 2010.

RPI Revista de Pesquisa Interdisciplinar, Cajazeiras, v. 1, Ed. Especial, 370 - 380, set/dez. de 2016. 
MUNIZ, C. A. Pedagogia: Educação e Linguagem Matemática. Brasília: Universidade de Brasília, Pedagogia de Início de Escolarização- Faculdade de educação em convênio com a SEEDF, 2003.

RPI Revista de Pesquisa Interdisciplinar, Cajazeiras, v. 1, Ed. Especial, 370 - 380, set/dez. de 2016. 